\title{
FATOR DE VISÃO DE CÉU E SOMBREAMENTO ARBÓREO EM ÁREA VERDE URBANA DE CLIMA TROPICAL
}

\author{
SKY VIEW FACTOR AND ARBOREAL SHADING IN URBAN GREEN AREA \\ OF TROPICAL WEATHER
}

\begin{abstract}
Diana Carolina Jesus de Paula1, Soneize Auxiliadora de Miranda², Denilton Carlos Gaio ${ }^{3}$, Flávia Maria de Moura Santos ${ }^{4}$, José de Souza Nogueira ${ }^{5}$, Marta Cristina de Jesus Albuquerque Nogueira ${ }^{6}$
\end{abstract}

\begin{abstract}
RESUMO
O microclima em áreas urbanas é determinado pelo balanço de energia, que depende de fatores geográficos e morfológicos, como as propriedades das superfícies e as variáveis meteorológicas. $\mathrm{O}$ objetivo deste estudo foi analisar a relação entre o Fator de Visão do Céu (FVC) e o microclima em diferentes níveis de sombreamento arbóreo em área verde urbana de clima tropical-úmido. A pesquisa foi desenvolvida por meio de monitoramento do microclima e a análise correlativa entre o FVC e as variáveis temperatura do ar, umidade relativa, temperatura da superfície e velocidade de vento. Os resultados obtidos demonstraram maior correlação $(R)$ entre os valores do $F V C$ e as variáveis temperatura da superfície e ventilação, comparada com os coeficientes obtidos para a temperatura do ar e umidade relativa.
\end{abstract}

Palavras-chave: Radiação solar; Microclima; Parque urbano.

\begin{abstract}
The microclimate in urban areas is determined by the energy balance, which depends on geographical and morphological factors such as the properties of surfaces and weather variables. The aim of this study was to analyze the relationship between the Sky View Factor (SVF) and the microclimate at different levels of tree shading in urban park of tropical-humid climate. The research was conducted by monitoring the microclimate and the correlative analysis between SFV and the variables air temperature, relative humidity, wind speed and surface temperature. The results showed a higher correlation $(R)$ between the values of SVF and the variables surface temperature and ventilation, compared to the coefficients obtained for the air temperature and relative humidity.
\end{abstract}

Keywords: Solar radiation; Microclimate; Urban park.

\footnotetext{
Recebido em 01.10.2016 e aceito em 03.11.2016

1 Arquiteta, Mestranda em Física Ambiental, Universidade Federal de Mato Grosso - Cuiabá-MT - arqdiana.paula@gmail.com 2 Arquiteta, Doutoranda em Física Ambiental, Universidade Federal de Mato Grosso - Cuiabá-MT - soneize@gmail.com 3 Físico, Dr. Professor do Programa de Pós-Graduação em Física Ambiental, UFMT- Cuiabá-MT - gaio@pgfa.ufmt.br 4 Arquiteta, Dra. Professora do Programa de Pós-Graduação em Física Ambiental, UFMT- Cuiabá-MT - flavia@gmail.com 5 Físico, Dr. Coordenador do Programa de Pós-Graduação em Física Ambiental, UFMT- Cuiabá-MT - nogueira@ufmt.br 6 Engenheira, Dra. Professora do Programa de Pós-Graduação em Física Ambiental, UFMT- Cuiabá-MT- mcjanp@gmail.com
} 


\section{INTRODUÇÃO}

Os espaços externos apresentam-se como ambientes essenciais nas atuais cidades contemporâneas, por favorecer o lazer, a estética e a qualidade ambiental urbana. Estudos relacionados a espaços verdes têm demonstrado a função exercida como regulador do microclima, atenuando os efeitos da ilha de calor urbano e da poluição, constituindo assim um clima próprio em relação ao espaço edificado envolvente (ABREU-HARBICH; LABAKI; MATZARAKIS, 2015; SPANGENBERG et al., 2008).

A cobertura vegetal apresenta-se como fator fundamental no equilíbrio higrométrico ambiental, advindo dos processos biológicos dos vegetais, destacando-se a fotossíntese e a transpiração, que estão associadas à absorção dos fluxos de ondas curtas, radiação fotossinteticamente ativa. Outros fatores associados à diversidade das espécies vegetais contribuem para a qualidade ambiental dos espaços urbanos, tais como o efeito de filtragem das ondas luminosas e das ondas sonoras proporcionadas por diferentes estruturas da vegetação, assim como a variabilidade dos componentes ambientais quanto aos aspectos físicos e subjetivos ao longo das estações do ano (MASCARÓ; MASCARÓ, 2010).

Shashua-Bar, Tsiros e Hoffman (2010) analisaram o microclima e a cobertura arbórea em ruas urbanas de diferentes configurações. A temperatura do ar apresentou forte correlação com o nível de cobertura arbórea, entretanto, o grau de arrefecimento na temperatura do ar apresentou correlação com outros fatores como a orientação das ruas e a intensidade de trafego de veículos.

Alguns parâmetros biofísicos da estrutura vegetal têm influência direta no intercambio de energia do sistema solo-vegetação-atmosfera tais como, as características da massa foliar que pode ser estimada pelo Índice de Área Foliar (IAF) e a definição quanto à abrangência ao bloqueio da radiação solar, estimada pelo índice de sombreamento arbóreo (OLIVEIRA et al., 2013). Pesquisa desenvolvida pelos mesmos autores em duas praças públicas na cidade de Cuiabá identificou a influência do sombreamento por cobertura arbórea nas variáveis temperatura e umidade relativa do ar, por meio do IAF das espécies identificadas e o Índice de Sombreamento Arbóreo (ISA) relativo à área total das praças avaliadas.

Sabe-se que o microclima em áreas urbanas é determinado pelo balanço de energia, que depende de fatores geográficos e morfológicos, como as propriedades das superfícies e as variáveis meteorológicas (MINELLA; ROSSI; KRUGER, 2011). A avaliação da obstrução da abóboda celeste à entrada da radiação solar pode ser obtida por estimativa ou por meio da determinação do Fator de Visão do Céu (FVC). Diferentes valores para o FVC definem a variação no balanço de radiação e, consequentemente, os diversificados níveis de armazenamento de energia. $O$ valor do FVC varia de 0 (zero) a 1 , sendo o valor 1 
correspondente a uma área sem qualquer obstáculo que se interponha entre o ponto de observação e o céu (OKE, 1981).

As relações entre o FVC e o comportamento da temperatura e umidade do ar são confirmadas em pesquisas desenvolvidas por OKE (1981), que observou a influência da geometria urbana e o papel do FVC na formação de ilhas de calor noturna em condições atmosféricas estáveis. O efeito sobre a temperatura do ar é proporcional à parcela de céu visível e as características termofísicas dos materiais das superfícies, dentre outros fatores temporais e espaciais, conforme observado por Yan et al. (2014) que identificaram forte correlação entre a elevação da temperatura do ar e o aumento do FVC, entretanto no período noturno a relação apresentou inversão, quanto menor o FVC maior a temperatura do ar, devido ao potencial de emissão da radiação de ondas longas após o por do sol.

Em área verde urbana com diferentes densidades de cobertura arbórea, Lin et al. (2012) propôs método analítico para estimar o nível de sombreamento por meio do FVC por área, considerando o conjunto dos valores pontuais do FVC das distintas áreas em um parque. Os resultados indicaram forte correlação entre o FVC de cada área do parque e as condições do ambiente térmico mais adequado aos usuários nas estações de verão e inverno.

Neste contexto, confirma-se a importância da avaliação do FVC, pois vários estudos referendam uma correlação com o balanço de energia do local, isto é, a estimativa do FVC é relevante para determinar o balanço de energia no interior de espaço verde urbano. $O$ objetivo deste estudo foi analisar a relação entre o FVC e o microclima em diferentes níveis de sombreamento arbóreo em área verde urbana de clima tropical.

\section{MATERIAL E MÉTODOS}

O estudo foi desenvolvido na cidade de Cuiabá, capital do estado de Mato Grosso, situada na região centro oeste brasileira, a $15^{\circ} 35^{\prime} 46^{\prime \prime}$ de latitude sul e $56^{\circ} 05^{\prime} 48^{\prime \prime}$ de longitude oeste, com altitude média inferior a $200 \mathrm{~m}$ acima do nível do mar. O perfil climático é o tropical continental semiúmido do tipo Aw, segundo a classificação de Köppen-Geiger, com duas estações caracterizadas por chuvas na primavera-verão e por seca acentuada no outonoinverno (Figura 1a).

A área selecionada para a pesquisa foi o parque estadual Massairo Okamura, localizado na região norte da malha urbana, possuindo 53,57ha de área pertencente a uma unidade de proteção ambiental, composta por floresta nativa e nascentes que constituem a cabeceira do córrego do Barbado, um dos cursos d'água contribuintes do Rio Cuiabá que corta 
a região metropolitana, sendo evitadas quaisquer intervenções no entorno e manutenção da cobertura vegetal nativa (Figura $1 b$ ).

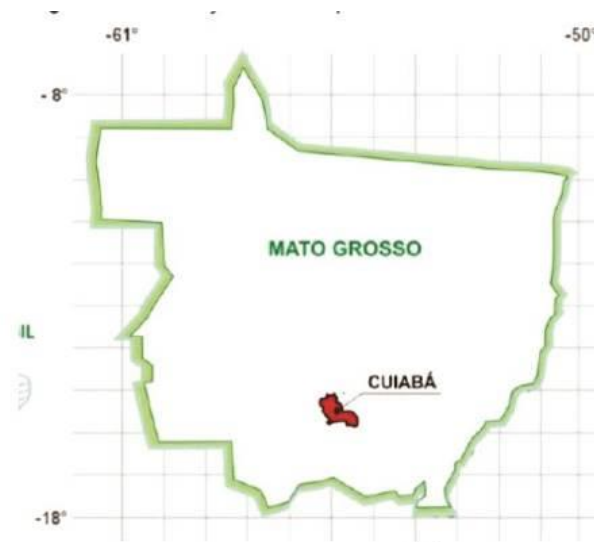

(a)

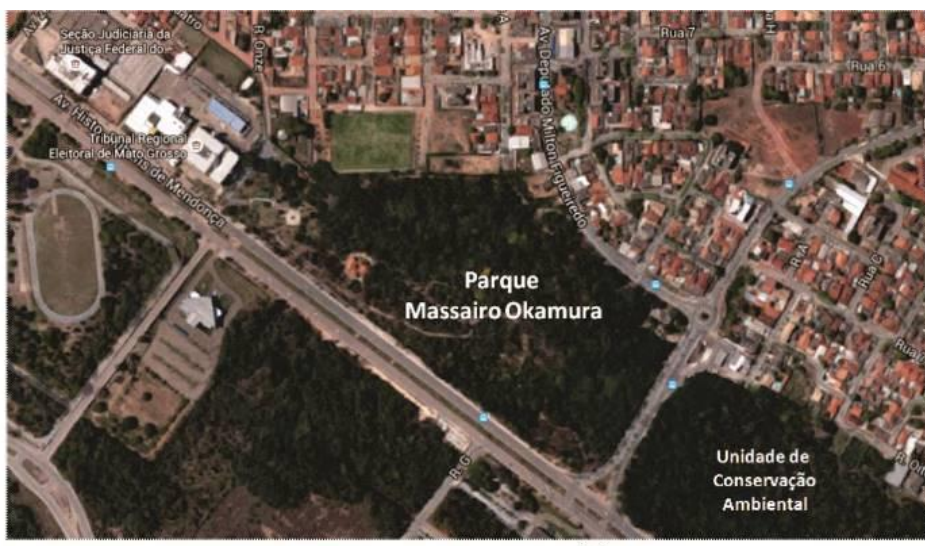

(b)

Fonte: (a) OLIVEIRA, 2011; (b) Google Earth adaptado pelos autores

Figura 1. (a) Localização da cidade de Cuiabá, (b) A área de estudo

Figure 1. (a) Location of the city of Cuiabá, (b) The study area

Com relação à vegetação do parque, segundo Arruda (2008), pode-se encontrar quatro tipos de vegetação bem definidas: a do tipo cerrado localizada próxima à entrada na parte superior com espécies típicas como a Curatella americana (lixeira) e outras; ao centro, próximos das nascentes predomina a vegetação ciliar; o terceiro tipo de vegetação encontrada é de transição, sendo uma mistura de Cerrado com Mata Ciliar com formação ripária, como a espécie Parapiptadenia rigida (Benth) Benan (angico-vermelho); a quarta e última é a exótica, sendo duas espécies a Leucaena spp. (leucena) e a Tectonagrandis (teca), estando presentes em áreas do parque, caracterizando o efeito de borda que pode proporcionar a diminuição da incidência de raios solares no interior do parque.

A área mais urbanizada do parque destinada ao lazer é composta por cerca de 2,0 km de trilhas para caminhada, praça central com equipamentos para atividades físicas, sanitários públicos, conjunto de edificações para as atividades administrativas e um centro para educação ambiental.

O método empregado foi a pesquisa exploratória, desenvolvida por meio dos seguintes procedimentos: monitoramento do microclima em um percurso da trilha existente no parque; definição do nível de sombreamento por meio do FVC nos pontos do percurso; análise da relação entre o FVC e o microclima na trilha para caminhada do parque.

O levantamento em campo foi desenvolvido em março de 2015, nos dias 23 e 24, 30 e 31, na estação de verão, período quente e úmido devido aos índices de precipitação na região. 
Para o monitoramento foram definidos 17 pontos e mais um de fechamento totalizando 18 pontos sobre o piso pavimentado da trilha (Figura 2).

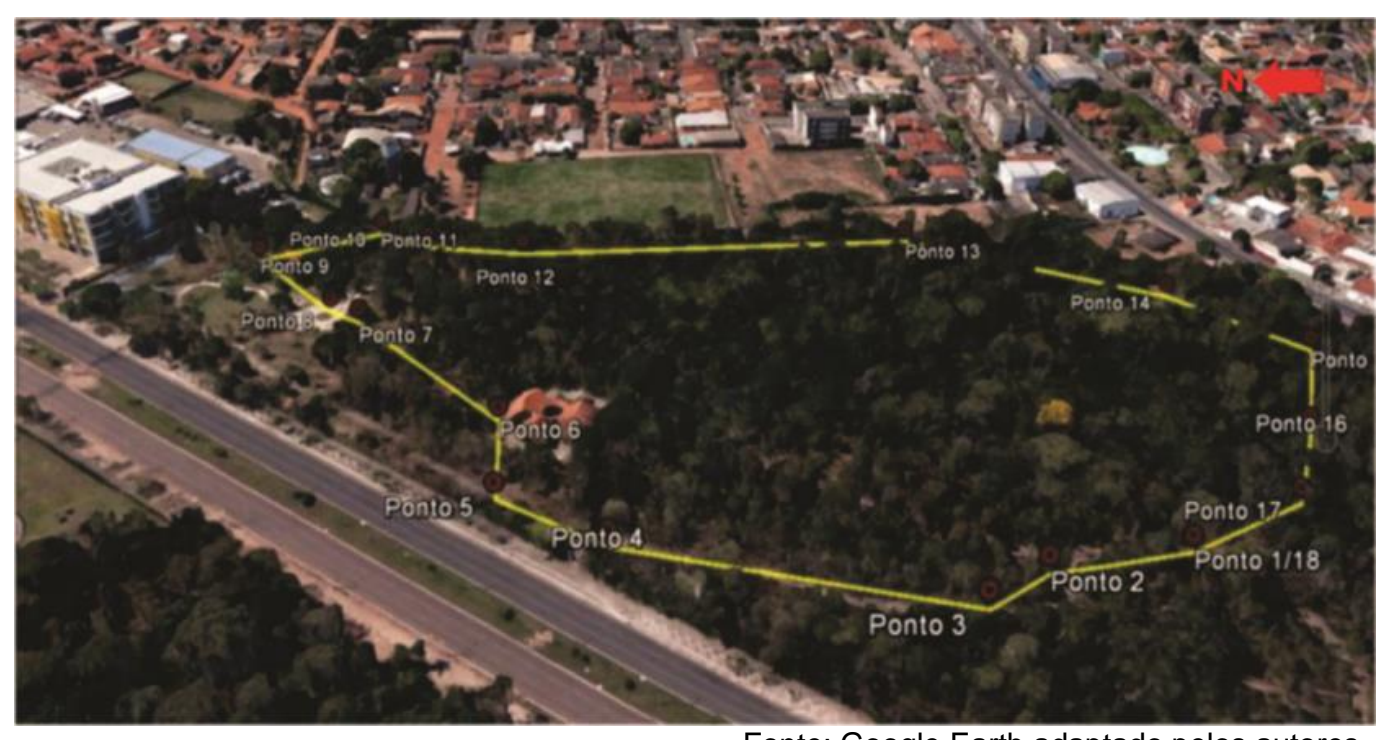

Fonte: Google Earth adaptado pelos autores

Figura 2. Percurso no parque e os pontos do transecto móvel

Figure 2. Path in the park and points of mobile transect

O percurso passa por diferentes áreas do parque. Na direção norte (trilha-norte) o percurso está situado em plano mais elevado do parque, altitude média de 224,60m, a área encontra-se mais urbanizada, com menor densidade arbórea e mais próxima dos limites com a área urbana. A trilha ao noroeste passa próxima a edificações existentes, contendo os pontos 4, 5, 6, 7 e 8 na praça central. A trilha a nordeste encontra-se próxima á divisa contendo os pontos $9,10,11$ e 12 . O percurso da trilha ao sul (trilha-sul) encontra-se em área de nível mais baixo do parque, altitude média de $215,51 \mathrm{~m}$, e com maior densidade arbórea. Na direção sudeste a trilha encontra-se junto ao limite do parque, contendo os pontos 13, 14 e o ponto 15. Na direção sudoeste a trilha é mais interna e passa pela floresta, contendo os pontos 16, 17, $1 / 18,2$, e o ponto 3 .

O monitoramento foi realizado por transecto móvel passando pelos 18 pontos sobre a trilha, executados em dois períodos, às $08 \mathrm{~h}$ e às $14 \mathrm{~h}$, sendo 8 aferições por ponto, que totalizaram 144 medições. A aferição das variáveis Temperatura do ar (Ta), Umidade Relativa do ar (Ur), Velocidade do vento (Vv) e a Temperatura da Superfície (Ts) sobre o piso da trilha, foram realizadas concomitantes, utilizando um termohigrômetro com data logger, modelo Hobo, com abrigo ventilado confeccionado em PVC; um anemômetro portátil de leitura instantânea e um termômetro infravermelho, ambos modelos Instrutherm. Os sensores de temperatura e umidade relativa do ar e o anemômetro foram posicionados a 1,10 m acima do solo, conforme a norma ISO 7726 (ISO, 1998). 
A estimativa do FVC foi obtida por método fotográfico com uma lente olho de peixe de $180^{\circ}$ (Figura 3), posicionada em cada ponto de medição na mesma altura dos equipamentos, 1,10 $\mathrm{m}$ acima do piso da trilha. Posteriormente as imagens foram editadas e inseridas no programa RayMan, desenvolvido e distribuído por Andreas Matzarakis (RayMan, 2010), sendo obtidos os diagramas hemisféricos e o valor do FVC dos pontos do monitoramento.
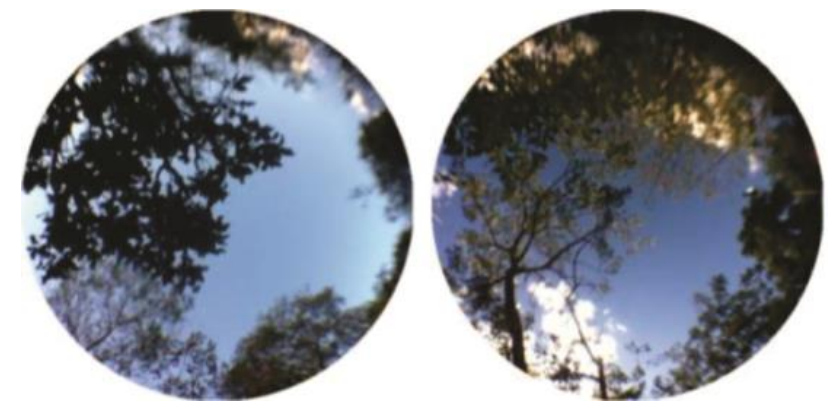

Figura 3. Imagens hemisféricas de pontos do transecto móvel
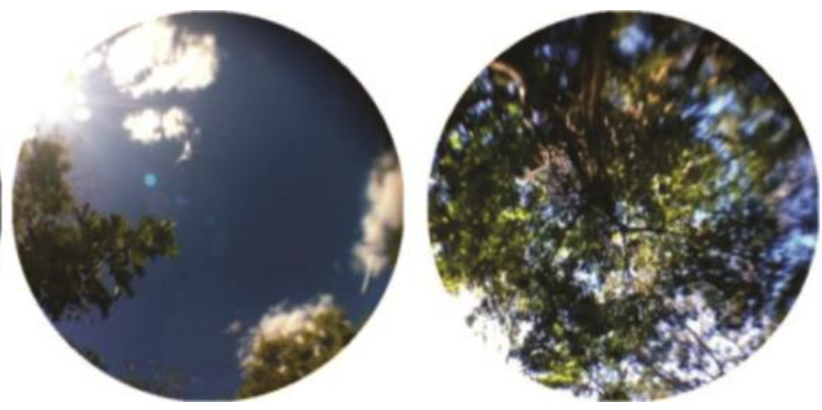

Fonte: Acervo dos autores

Figure 3. Hemispherical images of points of the mobile transect

Com relação ao sombreamento por elementos arbóreos, a forma da copa e a densidade foliar podem proporcionar diversidade quanto à efetiva obstrução à radiação solar incidente. Desse modo, foi realizada avaliação da incidência da Radiação Solar Direta (RSD), considerando os horários do monitoramento.

Para avaliação do grau de relação entre as variáveis monitoradas e o FVC, o coeficiente $\mathrm{R}$ de Pearson foi aplicado aos valores médios das variáveis para os quatro dias do monitoramento.

\section{RESULTADOS E DISCUSSÃO}

Entre os pontos monitorados os valores máximos estimados para o FVC foi de 0,975 no ponto p8 e de 0,800 no ponto p5, com menor obstrução da abóboda celeste, e os valores mínimos no ponto p12 de 0,092 e no ponto p13 de 0,098, com maior obstrução da abóboda celeste, devido às copas com maior densidade foliar (Figura 4). 

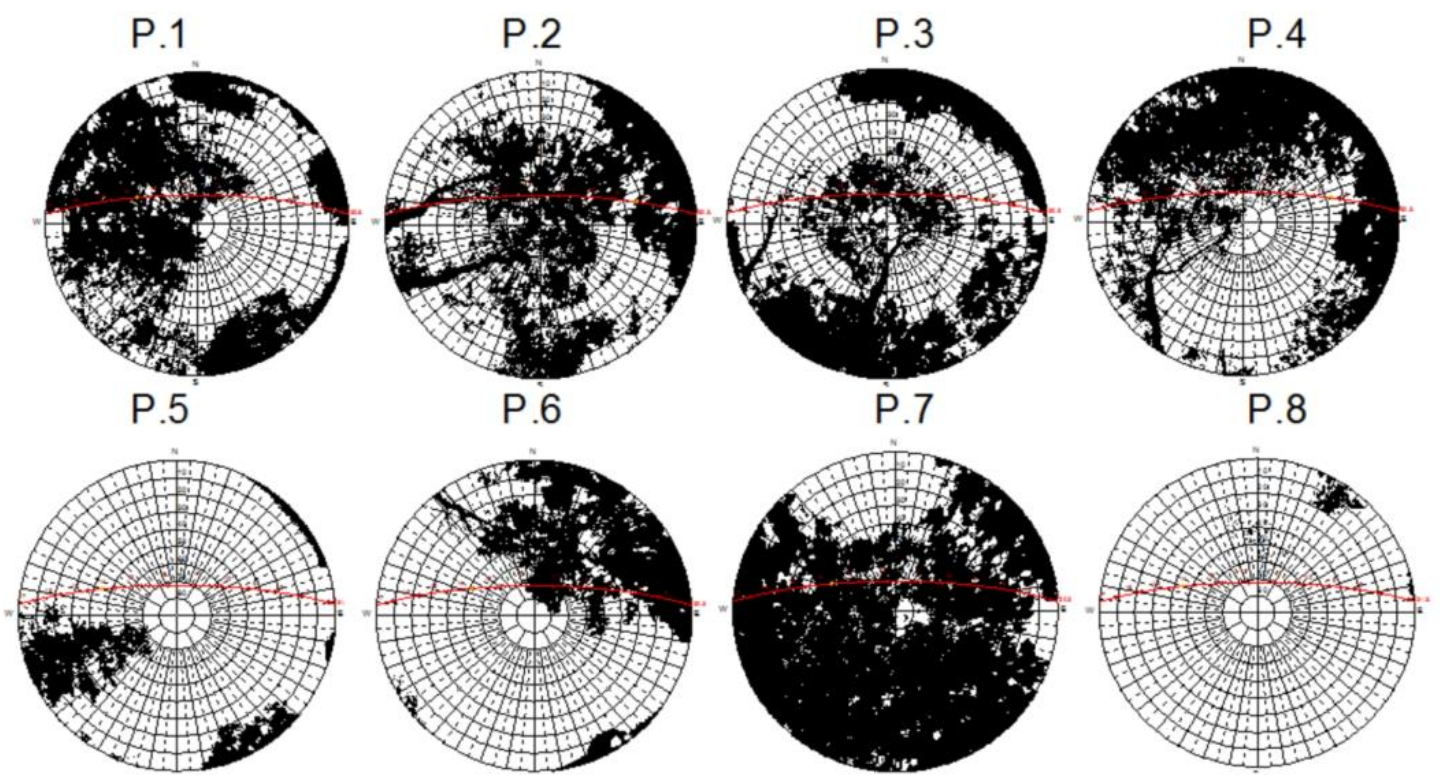

Figura 4. Arquivos de saída do RayMan, diagrama hemisféricos de pontos monitorados Figure 4. Output files of RayMan, hemispherical diagram of monitored points

Nos pontos 5, 8 e 14, com valores elevados para o FVC, a incidência da RSD ocorreu nos dois horários do monitoramento. Para os pontos 6 e 10, com valores do FVC de 0,315 e 0,590, respectivamente, a eficiência do sombreamento foi mais reduzida quando comparada com os pontos onde a maior densidade foliar da copa das árvores proporcionou sombreamento parcial nos dois horários do monitoramento (Tabela 1).

Tabela 1. Estimativa do FVC, localização e a incidência da Radiação Solar Direta (RSD)

Tabela 1. Estimated SVF, location and the incidence of Direct Solar Radiation (DSR)

\begin{tabular}{c|c|c|c|c}
\hline Pontos & FVC & Orientação & Altitude $(\mathbf{m})$ & RSD \\
\hline $\mathbf{1 / 1 8}$ & 0,345 & SO & 212,57 & - \\
$\mathbf{2}$ & 0,324 & SO & 215,78 & - \\
$\mathbf{3}$ & 0,402 & SO & 218,96 & - \\
$\mathbf{4}$ & 0,384 & NO & 219,19 & Manhã / tarde \\
$\mathbf{5}$ & 0,800 & NO & 220,29 & Tarde \\
$\mathbf{6}$ & 0,590 & NO & 220,97 & - \\
$\mathbf{7}$ & 0,120 & NE & 226,24 & Manhã / tarde \\
$\mathbf{8}$ & 0,975 & NE & 226,55 & - \\
$\mathbf{9}$ & 0,210 & NE & 228,08 & Tarde \\
$\mathbf{1 0}$ & 0,315 & NE & 227,30 & - \\
$\mathbf{1 1}$ & 0,150 & NE & 227,04 & - \\
$\mathbf{1 2}$ & 0,092 & NE & 225,78 & - \\
$\mathbf{1 3}$ & 0,098 & SE & 222,41 & - \\
$\mathbf{1 4}$ & 0,516 & SE & 220,33 & Manhã / tarde \\
$\mathbf{1 5}$ & 0,358 & SE & 216,91 & - \\
$\mathbf{1 6}$ & 0,238 & SO & 211,21 & 208,84 \\
$\mathbf{1 7}$ & 0,127 & SO & & \\
\hline
\end{tabular}




\section{O microclima no percurso monitorado}

Para os diferentes níveis do sombreamento arbóreo, expressos pelos FVC ao longo do percurso, no período da manhã a Ta apresentou variação média de 27,28 (p6) a 28,21 ${ }^{\circ} \mathrm{C}$ (p13). Na trilha-norte a média da Ta foi menor nos pontos p6, p7 e p5, comparada com as médias dos pontos p9, p10, p11 e p12, onde a Ta foi mais elevada que a do ponto p8 com maior valor do FVC e incidência da RSD nos dois horários do monitoramento. Na trilha-sul para os pontos p13, p14 e p15 a Ta foi mais elevada que a dos pontos mais internos na trilha junto à floresta (Figura 5a).

No período da tarde a Ta foi mais elevada, com variação de 29,50 (p18) a $30,41^{\circ} \mathrm{C}$ (p12), com comportamento semelhante ao do período da manhã, com as médias mais elevadas nos pontos mais próximos à divisa do parque, p10, p11 e p12, na trilha-norte e nos pontos p13, p14 e p15 na trilha-sul. Observou-se que, para os pontos mais sombreados localizados próximos aos limites do parque com a área urbana, a Ta foi mais elevada com redução dos valores da Ur para os quatro dias do monitoramento (Figura 5a).
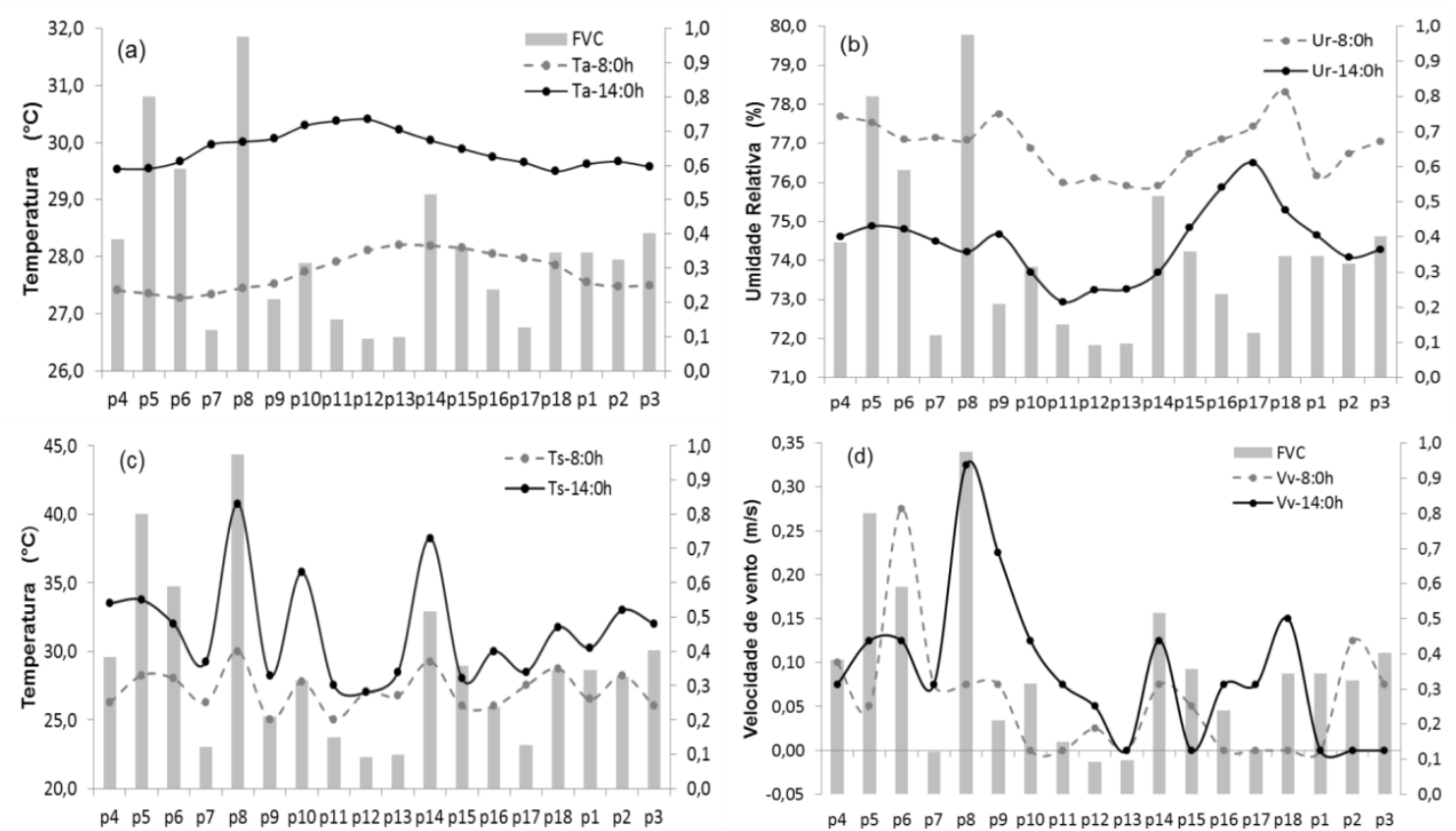

Figura 5. O FVC dos pontos na trilha e as médias das variáveis (a) temperatura e (b) umidade do ar, (c) temperatura da superfície e (d) velocidade do vento, ao longo do percurso

Figure 5. The SVF of points on the track and the means of variables (a) temperature and (b) air humidity, (c) surface temperature and (d) wind speed, along the way

A Ts no período da manhã apresentou menor variação, com médias de 25,0 (p9 e p11) a $30,0^{\circ} \mathrm{C}$ (p8) quando comparada com o período da tarde com médias de 27,0 (p12) a $40,75^{\circ} \mathrm{C}$ (p8). De modo geral os pontos com incidência da RSD apresentaram maior 
aquecimento da superfície, sendo os pontos p6 e p10 com incidência às $14 \mathrm{~h}$ e os pontos p5, p8 e p14 com incidência às $08 \mathrm{~h}$ e às $14 \mathrm{~h}$. Os pontos com as menores médias da Ts corresponderam aos maiores níveis de sombreamento, com valores do FVC de 0,210 e 0,092 (Figura 5c).

No período monitorado, a $\mathrm{Vv}$ apresentou valores reduzidos às $08 \mathrm{~h}$, tendo sido a média máxima registrada no p6 ( $F V C=0,590)$, enquanto a mínima de $0,0 \mathrm{~m} / \mathrm{s}$ foi registrada em 2 pontos na trilha-norte, pontos $\mathrm{p} 10(\mathrm{FVC}=0,315)$ e $\mathrm{p} 11(\mathrm{FVC}=0,150)$. Para o período da tarde a média máxima foi registrada no p8, junto à praça e com o maior valor do FVC. A média mínima de $0,0 \mathrm{~m} / \mathrm{s}$ ocorreu em 5 pontos na trilha-sul, p1, p2 e p3 junto à floresta e nos pontos p13 e p15, próximos à divisa e com FVC de 0,098 e 0,358, respectivamente (Figura 5d).

$\mathrm{Na}$ trilha-norte, em área mais elevada e com menor densidade arbórea, a ocorrência de vento foi maior com valor médio de $0,10 \mathrm{~m} / \mathrm{s}$, quando comparada com os pontos na trilha-sul, em área com menor elevação do parque e com maior rugosidade devido ao aumento da densidade arbórea, onde a média foi de $0,04 \mathrm{~m} / \mathrm{s}$.

Os resultados observados apontam que a magnitude dos efeitos do sombreamento, expresso pelo FVC, sobre o comportamento das variáveis aferidas podem diversificar de acordo com a configuração do entorno e das condições atmosféricas do período do dia, conforme observado em Shashua-Bar, Tsiros e Hoffman (2010).

\section{O sombreamento e as variáveis monitoradas}

Para a estimativa do efeito do sombreamento sobre as variáveis aferidas foi selecionado um ponto com maior valor do FVC, ou seja, a máxima exposição à radiação solar direta. Para o percurso da trilha-norte foi definido como referencial o p8 (R8) e para a trilha-sul o referencial foi o p14 (R14), conforme Figura 6.

$\mathrm{Na}$ trilha-sul, no ponto $\mathrm{p} 13$ a Ta foi mais elevada em até $0,18^{\circ} \mathrm{C}$ em relação ao ponto $\mathrm{R} 14$, nos demais pontos ocorreu redução da Ta com diferenças máximas de $-0,70^{\circ} \mathrm{C}$ no $\mathrm{p} 2$ às $08 \mathrm{~h}$ e de $-0,54^{\circ} \mathrm{C}$ no $\mathrm{p} 18$ às $14 \mathrm{~h}$. Na trilha-norte o efeito do sombreamento foi menor, com redução de $-0,17$ no $p 6$ às $08 \mathrm{~h}$ e de $-0,48^{\circ} \mathrm{C}$ no $\mathrm{p} 4$ às $14 \mathrm{~h}$. Nos pontos onde a Ta foi maior que a do ponto $\mathrm{R} 14$ as diferenças máximas foram de $0,65^{\circ} \mathrm{C}$ às $08 \mathrm{~h}$ e de $0,39^{\circ} \mathrm{C}$ às $14 \mathrm{~h}$ no ponto p12 (Figura 6a). Os efeitos do arrefecimento sobre a Ta apresentaram compatibilidade com os encontrados em Oliveira et al. (2013) com reduções máximas de $-0,56$ a $-0,74 \stackrel{\circ}{ } \mathrm{C}$ para o período quente e úmido, em relação ao sombreamento arbóreo em praças públicas. 


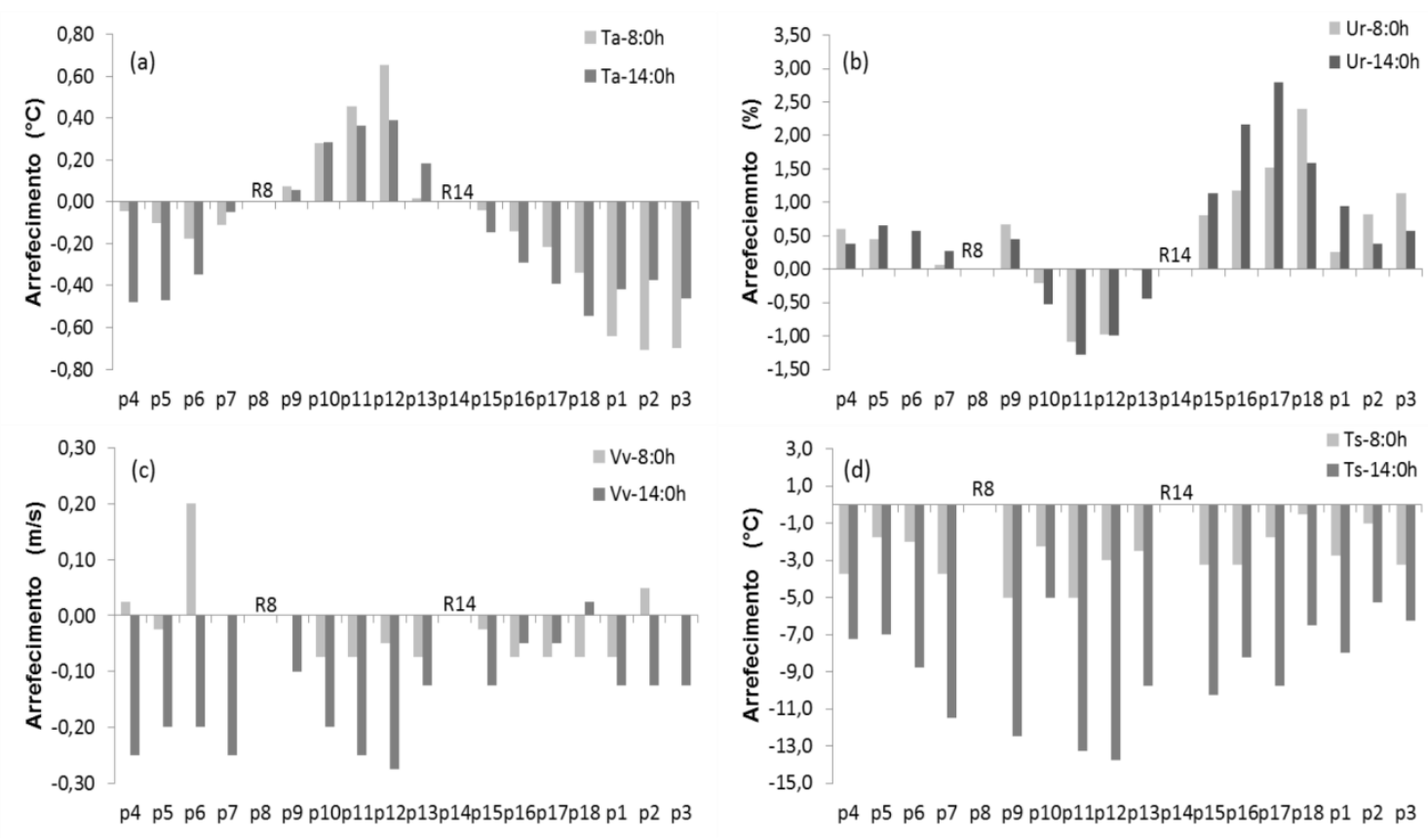

Figura 6. Efeito do sombreamento sobre as variáveis, (a) temperatura do ar, (b) umidade relativa, (c) velocidade do vento e $(\mathrm{d})$ temperatura superficial, às $08 \mathrm{~h}$ e às $14 \mathrm{~h}$

Figure 6. Effect of shading on the variables, (a) air temperature, (b) relative humidity, (c) wind speed and (d) surface temperature, at 08a.m and 02p.m.

Para a Ur ao longo do percurso nos pontos onde a Ta foi menor em relação ao ponto de referência, o sombreamento proporcionou a elevação da Ur, contudo, nos pontos onde a Ta foi mais elevada, entre os pontos p9 e p14, a Ur foi menor do que os pontos de referência. $\mathrm{Na}$ trilha-sul o efeito do sombreamento sobre a Ur proporcionou aumento máximo de 2,4\% no p18 às $08 \mathrm{~h}$ e de $2,8 \%$ no $\mathrm{p} 17$ às $14 \mathrm{~h}$. Na trilha-norte o efeito do sombreamento sobre a Ur foi menor com, diferenças máximas de 0,66\% para os pontos p9 às 08h e p5 às 14h (Figura 6b).

Os resultados podem ser atribuídos às condições atmosféricas do período com valores elevados da Ur, pois em diferentes condições atmosféricas o sombreamento por cobertura vegetal, frequentemente, apresenta efeitos mais elevados para a umidade do ar, comparada às áreas com menor cobertura arbórea, conforme valores encontrado por Martini et al. (2015) em avaliação comparativa de áreas com diferentes coberturas arbóreas.

O sombreamento proporcionou redução da Vv, com maior intensidade na trilha-norte, onde a redução máxima às $08 \mathrm{~h}$ ocorreu nos pontos p10 e p11, e às $14 \mathrm{~h}$ a redução foi mais acentuada no ponto $\mathrm{p} 12$, com maior obstrução do céu pela cobertura arbórea. Para trilha-sul o efeito do sombreamento sobre a $\mathrm{V} v$ foi menor, comparado aos pontos da trilha-norte, com valores máximos de $-0,13 \mathrm{~m} / \mathrm{s}$ em $62,5 \%$ dos pontos do percurso, conforme Figura $6 \mathrm{c}$. Os valores da redução foram baixos, porém, no período avaliado a média da $\mathrm{V} v$ foi reduzida com máxima de $0,33 \mathrm{~m} / \mathrm{s}$. Entretanto, o efeito do sombreamento sobre a $\mathrm{Vv}$ proporcionou redução percentual de 9 a $100 \%$ às $08 \mathrm{~h}$ e de 30 a $100 \%$ às $14 \mathrm{~h}$. Por conseguinte, os percentuais 
estimados foram superiores aos encontrados em Spangenberg et al. (2008), onde para arborização viária a redução da $\mathrm{V} v$ atingiu percentual máximo de 45\%.

Para a variável Ts o sombreamento proporcionou maior impacto nos pontos da trilhanorte onde a redução mínima da Ts foi de $-1,75^{\circ} \mathrm{C}(\mathrm{p} 5)$ às $08 \mathrm{~h}$ e os valores mais elevados com redução de $-11,50 \mathrm{a}-13,75^{\circ} \mathrm{C}$ às $14 \mathrm{~h}$ para os pontos $\mathrm{p} 7, \mathrm{p} 11$, e p12, com os menores valores do FVC do percurso. Na trilha-sul a redução da Ts foi menos acentuada, com diferença mínima de $-3,13^{\circ} \mathrm{C}(\mathrm{p} 2)$ e máxima de $-6,75^{\circ} \mathrm{C}(\mathrm{p} 15)$, com menor variação no efeito do sombreamento sobre a Ts, em consequência de menor amplitude, de 0,418, dos valores do FVC, comparada à maior variação do FVC dos pontos na trilha-norte com amplitude de 0,883 (Figura 6b). Os efeitos observados do sombreamento sobre a Ts corroboram com os resultados apontados por Ribeiro et al. (2015), que identificaram forte correlação entre o sombreamento arbóreo e o comportamento térmico de materiais comumente encontrados em superfícies urbanas, tais como: concreto, asfalto e solo exposto.

\section{Correlação entre o FVC e as variáveis monitoradas}

A correlação entre os valores do FVC e as variáveis monitoradas foi estimada pelo coeficiente de correlação de Pearson. Para as variáveis $T a, V_{v}$ e a Ts a correlação foi significativa com coeficiente $R>0,50$, entretanto, entre os valores da Ur e os valores do FVC a correlação não foi significativa com coeficiente $R<0,50$. A menor correlação entre Ur e o FVC pode ser justificada em razão das condições atmosféricas, com elevada precipitação no período úmido da região, sendo que, a maior concentração de vapor de água no ar atenuou os efeitos da cobertura vegetal sobrea a umidade relativa no período monitorado (Figura 7b).

Entre a temperatura do ar e o FVC a correlação foi inversa em razão dos pontos (p9 ao p13) com menor FVC, ou seja, maior nível de sombreamento, terem apresentado redução significativa da $\mathrm{Vv}$, o que propiciou a redução das trocas convectivas e o consequente aumento da Ta em relação aos pontos de referência (Figura 7a). Observou-se que outro fator que pode ter contribuído para elevação da Ta nos referidos pontos foi o efeito de borda, uma vez que os mesmos estão localizados mais próximos aos limites do parque com o bairro residencial. $O$ efeito de borda em parque urbano foi observado por Andrade, De Musis e Sanches (2015), que encontrou diferença de até $1,7^{\circ} \mathrm{C}$ entre as áreas mais centrais e as áreas mais próximas ao limite de um parque inserido na área urbana. 

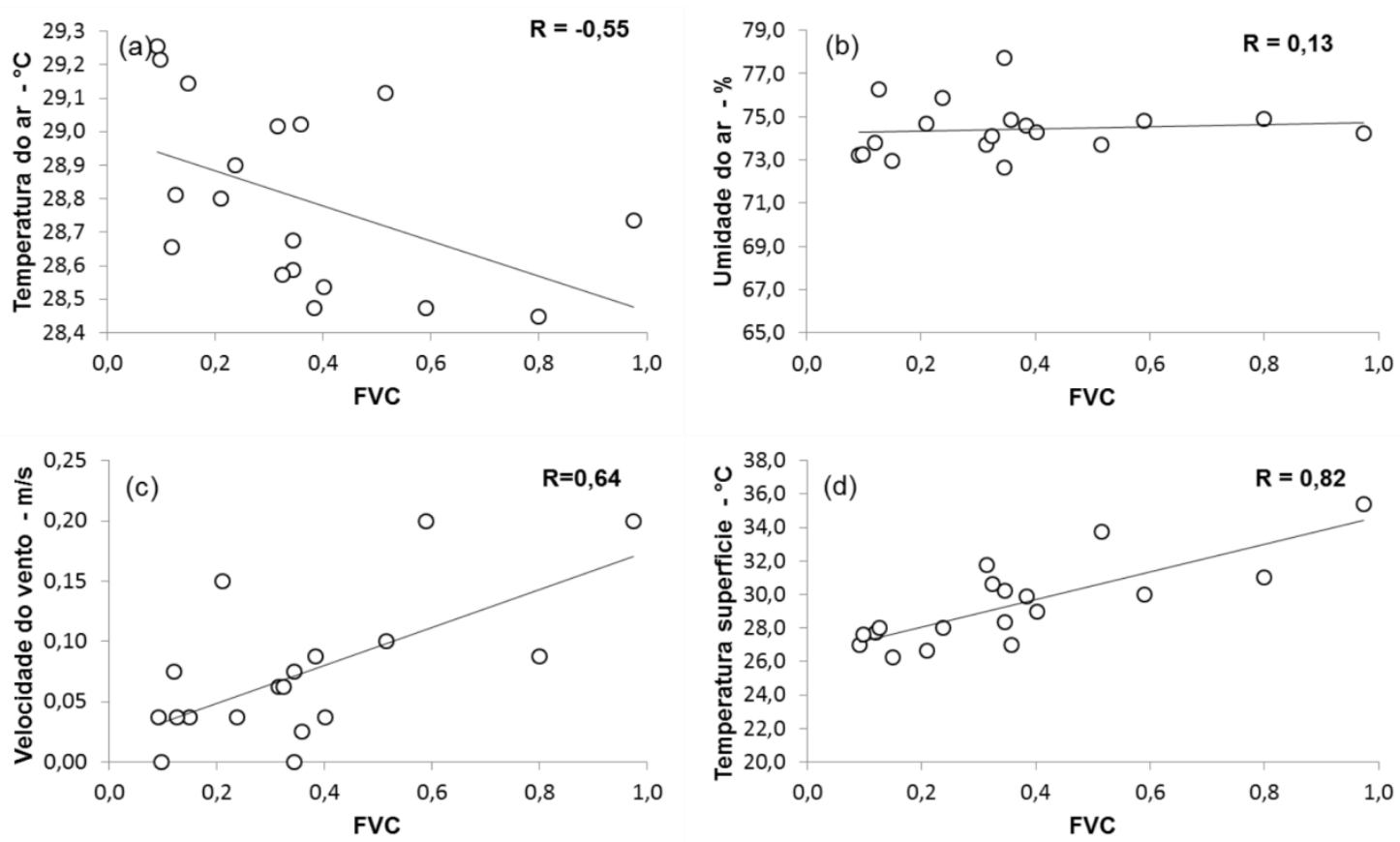

Figura 7. Relação (R) entre o FVC e as variáveis (a) temperatura do ar, (b) umidade relativa, (c) velocidade do vento e (d) temperatura da superfície

Figura 7. Correlation (R) between SVF and the variables (a) air temperature, (b) relative humidity, (c) wind speed and (d) surface temperature

Para a variável Vv a relação entre os valores do FVC foi moderada, onde os pontos com maior obstrução do céu apresentaram redução significativa da Vv (Figura 7c). Destaca-se que outros fatores também contribuíram para o comportamento da ventilação no percurso avaliado, como a diferença de nível e de densidade da cobertura arbórea entre a área da trilhasul e a área da trilha-norte.

A maior correlação obtida para a variável Ts demonstrou que os valores do FVC expressaram com maior aproximação a relação entre a radiação solar incidente e o nível de sombreamento sobre a superfície da trilha (Figura 7d). Kong et al. (2016) identificaram uma forte correlação entre o FVC, as variáveis microclimáticas e as características do dossel arbóreo em fragmentos de áreas verdes urbanas. No percurso avaliado entre os valores do FVC o nível de sombreamento foi elevado em $46,7 \%$ dos pontos, para $40,0 \%$ o nível de sombreamento foi médio e em $13,3 \%$ dos pontos o nível de sombreamento foi mais reduzido, o que contribuiu para o grau de correlação entre o sombreamento e a Ts dos pontos sobre a trilha no parque. 


\section{CONCLUSÕES}

$\mathrm{Na}$ análise de correlação entre o FVC e o microclima em diferentes níveis de sombreamento, proporcionada por espécies arbóreas do cerrado em um parque urbano, verificou-se maior correlação entre os valores do FVC e a variável temperatura da superfície, seguida da variável velocidade do vento sob as copas das espécies arbóreas do percurso avaliado.

A variável temperatura do ar apresentou correlação fraca com os valores do FVC, e correlação não significativa para a variável umidade relativa do ar. Os resultados demostraram que outros fatores podem afetar a relação entre o FVC e o microclima local, tais como, a maior umidade atmosférica do período chuvoso, a redução da ventilação proporcionada pelo dossel arbóreo e o possível efeito de borda sobre os pontos com maior proximidade aos limites com a área construída no entorno do parque.

O emprego do FVC para quantificar o nível de sombreamento apresentou resultado satisfatório devido a maior precisão obtida pelo método fotográfico, no registro da obstrução da abóboda celeste sob as copas de árvores, assim como, a possibilidade proporcionada pelo método na identificação da incidência da radiação solar direta de acordo com a configuração do dossel arbóreo.

\section{REFERÊNCIAS}

ABREU-HARBICH, L V; LABAKI, L C; MATZARAKIS A. Effect of tree planting design and tree species on human thermal comfort in the tropics. Landscape and Urban Planning, Amsterdam, n.138, p.99-109, 2015.

ANDRADE, L. P. de; DE MUSIS, C. R.; SANCHES, L. As áreas urbanizadas limítrofes ao parque ecológico Mãe Bonifácia e os efeitos sobre os elementos climáticos: um estudo do efeito de borda. In: XII CONGRESSO DE ECOLOGIA DO BRASIL, 2015, São Lourenço-MG, Anais... São Lourenço: XIICEB, p.1-3, 2015.

ARRUDA, J. L. Avifauna, mastofauna e repitilia do Parque Estadual Massairo Okamura, Cuiaba, MT. Estudos de Biologia, Curitiba, n.30, p.99-106, 2008.

INTERNATIONAL ORGANIZATION FOR STANDARDIZATION (ISO). ISO 7726: thermal environments: instruments and methods for measuring physical quantities. Switzerland, 1998.

KONG, F.; YAN, W.; ZHENG, G.; YIN,H.; CAVAN, G.; ZHAN, W.; ZHANG, N.; CHENG, L. Retrieval of three dimensional tree canopy and shade using Terrestrial Laser Scanning (TLS) data to analyze the cooling effect of vegetation. Agricultural and Forest Meteorology, Ontário, n. 217, p. 22-34, 2016. 
LIN, T-P.; TSAI K-T.; HWANG, R-L.; MATZARAKIS A. Quantification of thee effect of thermal indices and sky view factor on park attendance. Landscapeand Urban Planning, Amsterdam, n.107, p.137-146, 2012.

MARTINI, A.; BIONDI, D.; BATISTA, A. C.; SILVA FILHO, D. F. da. Microclima em diferentes tipologias de floresta urbana. Revista da Sociedade Brasileira de Arborização Urbana, Piracicaba, v.10, n.4, p. 12-22, 2015.

MASCARÓ, L.; MASCARÓ, J. Vegetação urbana. 3 ed., Porto Alegre: Mais Quatro, 2010, p. 204.

MINELLA, F. O.; ROSSI, F. A.; KRUGER, E. J. Análise do efeito diurno do fator de visão do céu no microclima e nos níveis de conforto térmico em ruas de pedestres em Curitiba. Ambiente Construído, Porto Alegre, v. 11, n. 1, p. 123-143, 2011.

OLIVEIRA, A. S.; NOGUEIRA, M. C. J. A.; SANCHES, L.; NOGUEIRA, J. S. Variáveis meteorológicas e cobertura vegetal de espécies arbóreas em praças urbanas em Cuiabá, Brasil. Revista Brasileira de Meteorologia, São Paulo, v. 28, n. 4, p. 389-400, 2013.

OKE, T. R. Canyon geometry and the nocturnal urban heat island: comparison of scale model and field observations. International Journal of Climatology, London, vol.1, n.3, p. 237-254, 1981.

RAYMAN, 2010. Disponível em: <http://www.mif.uni-freiburg.de/RayMan>. Acesso em 12/junho /2015.

RIBEIRO, K. F. A.; VALIN JR M. de O.; SANTOS, F. M. de M.; NOGUEIRA, M. C. de J A.; NOGUEIRA, J. de S.; DE MUSIS C. R. Análise da temperatura interna e superficial em diferentes sombreamentos arbóreos. Revista da Sociedade Brasileira de Arborização Urbana, Piracicaba, v.10, n.2, p. 40-60, 2015.

SHASHUA-BAR, L.; TSIROS, I. X. ; HOFFMAN M. E. A modeling study for evaluating passive cooling scenarios in urban streets with trees. Case study: Athens, Greece. Building and Environment, Oxford, n. 45, p. 2798-2807, 2010.

SPANGENBERG, J.; SHINZATO, P.; JOHANSSON, E.; DUARTE, D. Simulation of the influence of vegetation on microclimate and thermal comfort in the city of São Paulo. Revista da Sociedade Brasileira de Arborização Urbana, Piracicaba, v.3, n. 2, p. 1-19, 2008.

YAN, H.; FAN, H. S.; GUO, C.; WU, F.; ZHANG, N.; DONG, L. Assessing the effects of landscape design parameters on intra-urban air temperature variability: The case of Beijing, China. Building and Environment, Oxford, n.76, p. 44-53, 2014. 